\title{
O USO DA ANALISE DE COMPONENTES PRINCIPAIS E NDVI COMO SUBSIDIO AIDENTIFICAÇÃO DE ALTERAÇÕES NA VEGETAÇÃO: UMA ANÁLISE DO ENTORNO DAMINA CBA/ITAMARATI DE MINAS
}

Fabricio Sousa da Silva*

Fábio Soares de Oliveira*

\section{Resumo}

A exploração mineral é intensa no Estado de Minas Gerais, não sendo, por tanto, isenta de problemas Ambientais. Nesse sentido, este artigo tem como objetivo avaliar duas técnicas estatísticas de detecção de alterações na vegetação, tomando como base para tal o entorno da exploração de calcário em Itamarati de Minas, Minas Gerais.

Palavras-chave:Análise por componentes Principais, NDVI, Supressão de Vegetação.

\begin{abstract}
Mineral exploration is intense in the State of Minas Gerais, and is not therefore, exempt from environmental problems. Accordingly, this article aims to evaluate two statistical techniques for detecting changes in vegetation, taking as a basis for this, the area surrounding the exploitation of limestone in Foreign Ministry of Mines, Minas Gerais.
\end{abstract}

Keywords: Principal component analysis, NDVI, suppression of vegetation.

\footnotetext{
*Mestrando em Análise e Modelagem de Sistemas Ambientais pelo IGC/UFMG.fabriciosousasilv@gmail.com

* Professor do Departamento de Geografia no IGC/UFMG. fabiosolos@gmail.com 


\section{1- INTRODUÇÃO}

Para que se obtenha precisão e valor nas informações extraídas de uma imagem através de seu processamento, diversas técnicas são utilizadas. Menezes e Almeida (2012), Moreira (2011), entre outros autores, destacam como técnicas importantes para tal, o realce, a descorrelação de dados, os filtros, a ACP, a subtração de bandas, o NDVI, além de tantas outras técnicas matemáticas que são aplicadas à matriz de dados (uma imagem digital).

A Análise por componentes Principais tem sua ideia oriunda na estatística multivariada (Hair et al.,1998), utilizada na resolução de problemas de redundância de dados, esta redundância gera uma grande dimensionalidade no espaço de atributo dos dados. A redundância de dados ocorre durante a aquisição de informações, em sensoriamento remoto por conta da proximidade da resposta espectral de diferentes alvos nas bandas espectrais.

No processamento digital de imagens, a Análise por Componentes Principais (ACP) tem a função de retirar a redundância de informações adquiridas na captação referente a cada banda, bem como a eliminação da dualidade de informações espectrais que prejudicam a interpretação dos dados pelo operador. Pode ser ainda utilizada para identificação de uma mesma feição em bandas diferentes a partir de uma nova banda gerada (novo fator), uma nova componente.

Outra técnica, mais simples, porém muito usual, é o Índice de Vegetação Normalizado, o NDVI, que se constitui de um índice (variando de -1 a 1) que identifica a intensidade da vegetação em dado espaço. Esse índice realça ainda feições mais simples como gramíneas.

Com o auxilio das técnicas mencionadas, este artigo objetiva a analise de alterações na vegetação, no entorno da mina de calcário em Itamarati de minas, estado de Minas Gerais, verificando o poder de explicação de ambos os métodos estatísticos na caracterização multitemporal da área.

\section{2- MATERIAIS E MÉTODOS}

\subsection{Materiais}

Foram utilizadas Imagens Landsat 5- TM da Mina de Calcário da CBA em Itamarati de Minas, referente aos anos de 1990 e 2010, de antes da implantação da exploração até a atualidade. 
Para essa pesquisa, seguiu-se os procedimentos de acordo com Sousaet al (2009) para ACP em vegetação e, considerou-se as bandas 4 e 3, que representam as melhores informações a cerca da vegetação (as mesmas utilizadas no procedimento de índice de vegetação). Para essas bandas, utilizamse as informações não correlacionadas da vegetação em ambas abandas, através da geração de uma componente principal. Foi executado no Envi 4.7 o empilhamento 1 para o par de bandas 3/4 de 1990 e empilhamento (2) para o par 3/4 de 2010, em seguida executou-se a transformação por Analise de componentes Principais para um par para cada ano.

Após a transformação, escolheu-se a segunda componente de cada ano, uma vez que essa não possui informação redundante da vegetação, apresentando uma baixa correlação, e posteriormente utilizou-se uma classificação não supervisionada, $\mathrm{k}$ - médias, com o intuito de se verificar o espalhamento da vegetação ao longo da cena. Para isso, a imagem foi classificada em duas classes: vegetação (verde) e outras feições (amarelo).

Ainda na plataforma ENVI executou-se uma transformação para Índice de vegetação normalizada para ambos os pares de empilhamento, em seguida executou-se uma mesma classificação K-médias, com interferência do usuário. Por fim, um comparativo estatístico foi realizado com o intuito de verificar o potencial da informação retirada mediante a análise de componentes principais.

\subsection{Métodos}

\subsubsection{Análise por componentes principais e NDVI}

A Análise por Componentes Principais (ACP) é um método da estatística multivariada usada para analisar inter-relações entre um grande número de variáveis e, explicar essas variáveis em termos de suas dimensões inerentes comuns em uma forma mais compacta.

De acordo com Hair et al. (1998), o objetivo da ACP consiste em encontrar um meio de condensar a informação contida nas variáveis originais em um conjunto menor de variáveis estatísticas com perda mínima de informações. O produto dessa condensação é um novo fator que, de acordo com Sirtolli (1998), este novo fator (ou uma nova dimensão reduzida) evidencia uma informação antes ofuscada pela repetência no espaço dos atributos.

Os autovetores, também chamados de componentes, representam a quantidade de novos fatores gerados. Eles carregam uma quantidade de informação, denominada autovalor. $\mathrm{O}$ autovetor carrega a informação para a explicação da variância desse dado fator. Dessa forma, utiliza-se o 
componente que possui a maior variância (ou seja, menor correlação), logo ele carrega a maior quantidade de informação do nosso objeto de estudo, uma vez que o objetivo aqui não é identificar a correlação de informações da vegetação, mas sim sua variação temporal ao longo dos pares 3 e 4 de bandas de cada período.

A Análise por componentes principais ainda possui outra importância no PDI, após a redução da dimensionalidade dos dados, aumenta a eficiência computacional de acordo com Sirtolli (1998).

O índice de Vegetação Normalizado, proposto por Rouse et al. (1973), é resultado da diferença de reflectância entre o infravermelho próximo (NIR) e o vermelho (Red) dividida pela soma das faixas NIR e RED. Ele evidencia apenas a vegetação, uma vez que é a única feição que apresenta um comportamento diferente nas duas bandas citadas (figura 1).

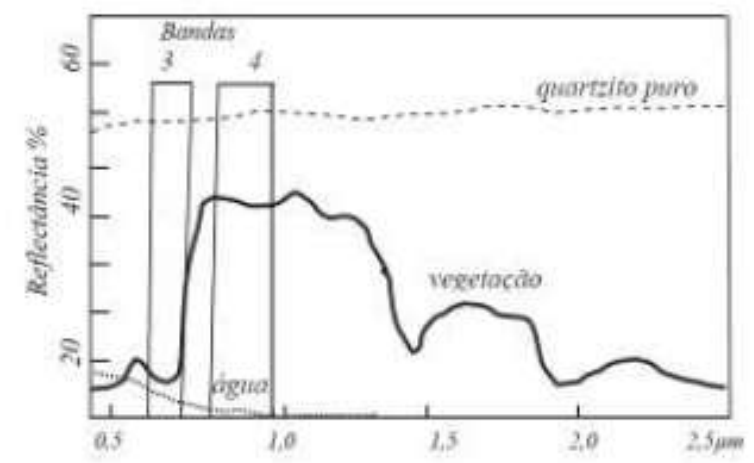

Figura 1: Comportamento espectral da vegetação nas bandas 3 e 4 Landsat 5TM. Fonte: Menezes e Almeida, 2012.

Outros elementos apresentam o mesmo comportamento, logo, o valordessas feições no índice será nulo, por conta da divisão dos seus valores aproximados.

\section{3 - RESULTADOS}

O empilhamento 1 (formado pelo par de bandas TM3 E TM4 de 1990) foi transformado em componentes principais e retirada para análise, apenas a segunda componente, uma vez que de acordo com a tabela 1 esta componente exibiu menor correlação entre os dados da banda, realçando assim os dados da vegetação. 
Tabela1.Dadosestatísticos doempilhamento1.

\begin{tabular}{|c|c|c|c|c|}
\hline Bandas & Média & D. Padrão & Componente & Informação \\
\hline 1 & $20.216,320$ & $6.956,815$ & 1 & $73,95 \%$ \\
\hline 2 & $65.026,421$ & $21.539,888$ & 2 & $26,05 \%$ \\
\hline
\end{tabular}

A componente 2 do empilhamento 1 apresenta a vegetação em tons mais claros e, outras feições em tons mais escuros. O objetivo é identificar a configuração da vegetação e de outras feições, incluindo corpos hídricos e solo exposto (figura 2).

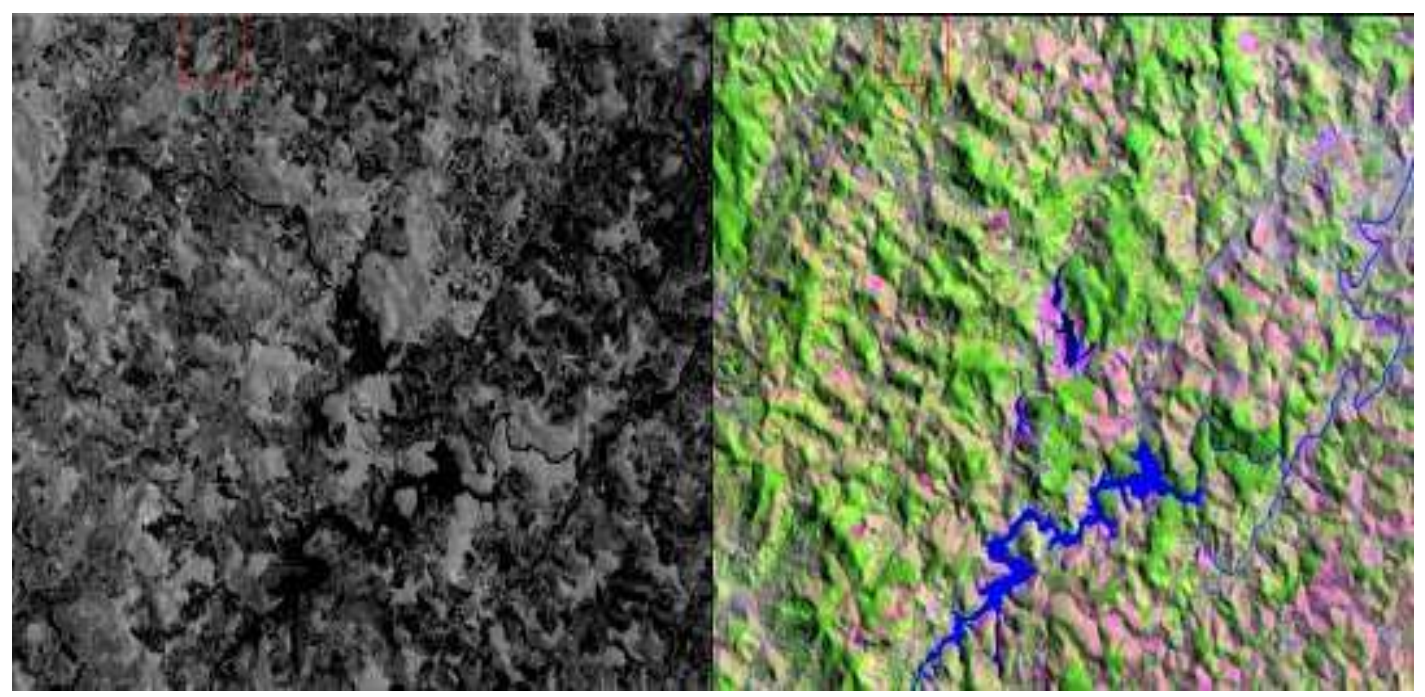

Figura 2:Comparativo entre a 2 componente e a composição colorida RGB 543/1990. Os tons mais claros se referem a vegetação.

O resultado da componente foi transformado em uma classificação não-supervisionada kmédias que, leva em conta os valores da componente enão mais a resposta espectral do alvo (para esse caso em análise). Nesse momento, passou-se a trabalhar com a estatística da componente (figura 3). 


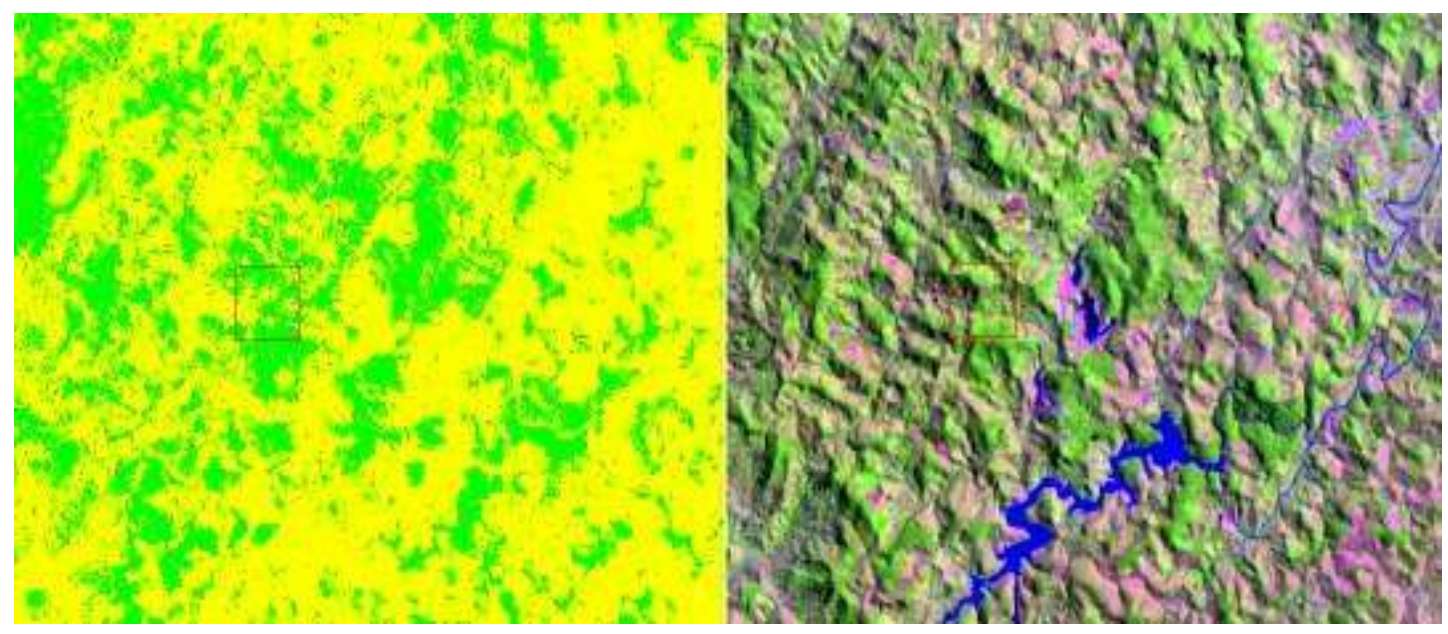

Figura 3:Comparativo RGB para uma classificação k-média.

O resultado da classificação K-médias, a partir de uma análise visual, foi extremamente satisfatório no que se refere à vegetação, esse método identificou com grande precisão os valores gerados na segunda componente que se referem à vegetação, aqui exibidos em tom verde.

O empilhamento 2 (formado pelo par de bandas TM3 E TM4 de 2010) foi transformado em componentes principais e retirada, para análise apenas, a segunda componente, uma vez que de acordo com a tabela 2, apresenta menor correlação entre os dados das bandas, realçando assim os dados da vegetação.

Tabela2: Dados estatísticos do empilhamento2

\begin{tabular}{|c|c|c|c|c|}
\hline Bandas & Média & D. Padrão & Componente & Informação \\
\hline 1 & 18.385630 & 7.209315 & 1 & $76,36 \%$ \\
\hline 2 & 60.197877 & 21.012533 & 2 & $23,64 \%$ \\
\hline
\end{tabular}

Semelhante ao procedimento anterior a vegetação está exibida em tonsmais claros e outras feições em tons mais escuros (figura 4). 


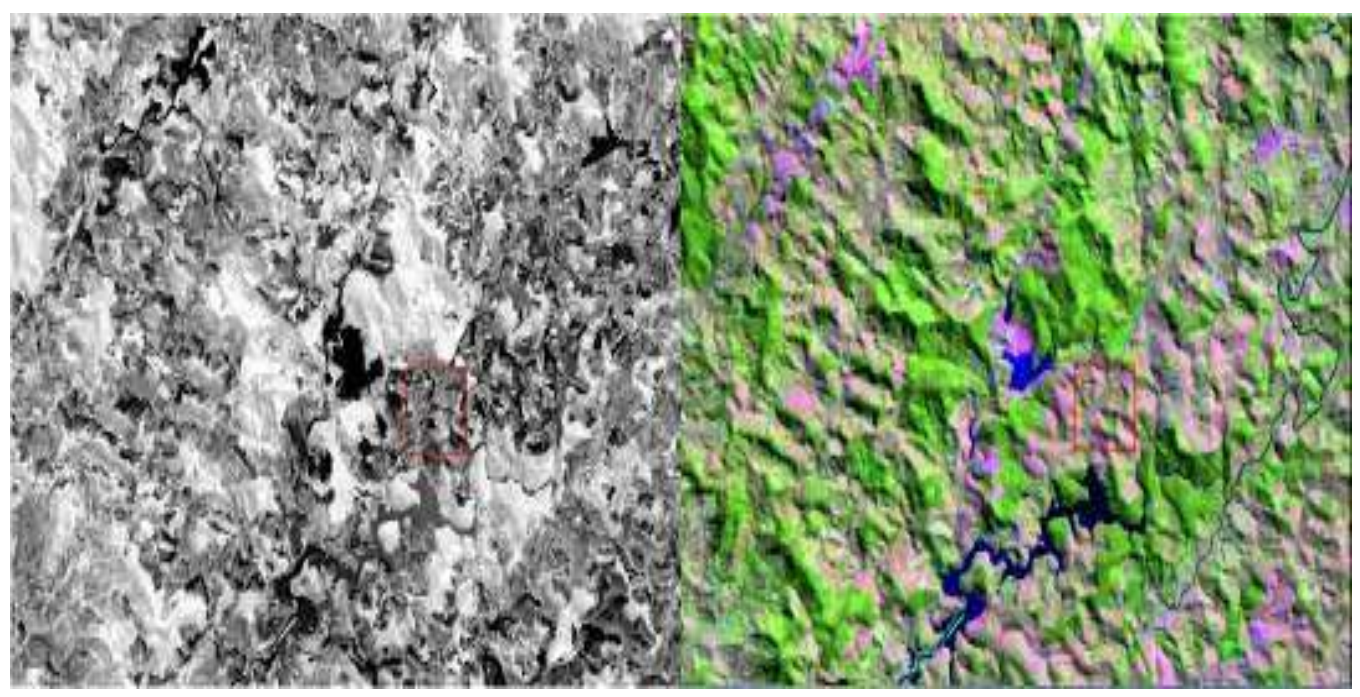

Figura 4: Comparativo entre a 2 componente e composição colorida RGB543/2010. Os tons mais claros se referem a vegetação.

O resultado da segunda componente foi classificado em um métodonão supervisionado kmédias, conforme o procedimento realizado na imagem de 1990 (figura 5).

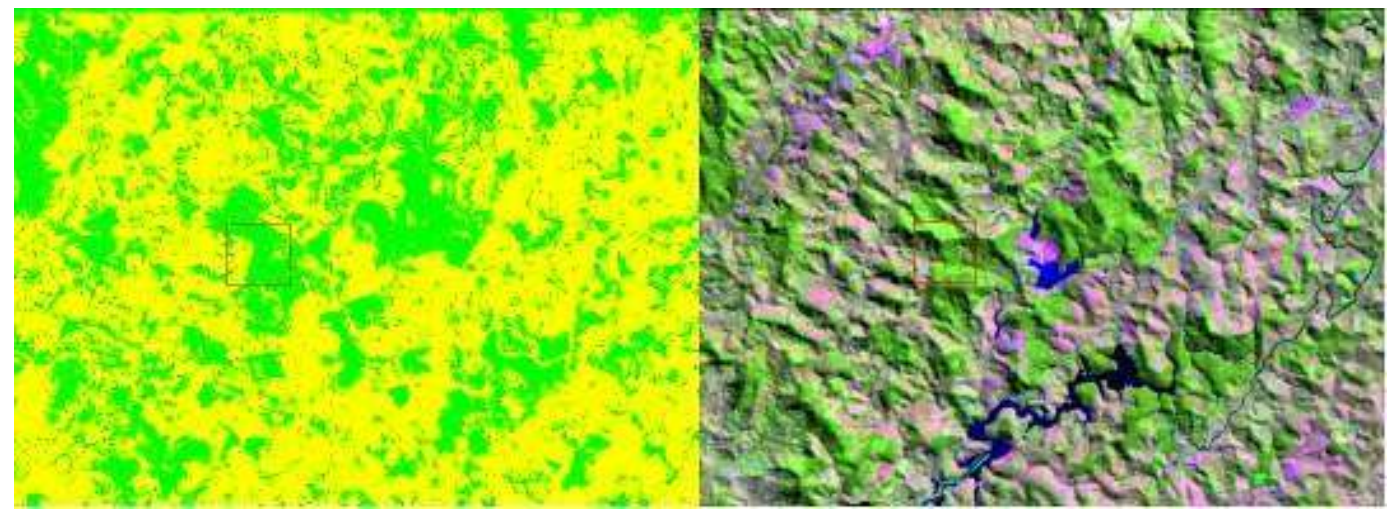

Figura 5:Comparativo entre as feições da imagem e as duas classes geradas pela classificação Kmédias.

A posterior gerou-se os valores estatísticos do NDVI de cada ano aqui estudado. Utilizando ferramenta de estatística do Envi, notou-se que a classe vegetação apresentou, para ambos os métodos, um aumento. A variação entre a análise de componentes principais e os valores extraídos via NDVI são descritos na tabela 3.

Tabela 3: Comparativo multitemporal entre métodos. 


\begin{tabular}{|c|r|r|c|}
\hline MÉTODO & ANO & $\left(\mathrm{KM}^{2}\right)$ & $\%$ \\
\hline ACP & $\mathbf{1 9 9 0}$ & $\mathbf{5 9 , 4 3}$ & $\mathbf{2 8 , 8 0 \%}$ \\
\hline NDVI & 1990 & 63,65 & 30,2 \\
\hline ACP & $\mathbf{2 0 1 0}$ & $\mathbf{7 0 , 3 8}$ & $\mathbf{3 2 , 3 4}$ \\
\hline NDVI & 2010 & 71,736 & 33,8 \\
\hline
\end{tabular}

Os dois métodos estatísticos mostraram que não houve impacto significativo na vegetação por conta da atividade mineradora. Ambos ressaltam o crescimento dessa feição nas cenas. 